\title{
A saúde docente no trabalho: apontamentos a partir da literatura recente
}

\author{
Teachers health in the workplace: evidence from recent \\ literature
}

\author{
Pedro Afonso Cortez¹, Marcus Vinícius Rodrigues de Souza², \\ Laura Oliveira Amaral ${ }^{1}$, Luiz Carlos Avelino da Silva ${ }^{1}$
}

\begin{abstract}
Resumo
Introdução: A saúde no trabalho docente apresenta-se como um tema relevante. Verifica-se o crescimento do adoecimento docente no trabalho, mas poucas ações são desenvolvidas em relação às legislações e políticas específicas que privilegiam a saúde do professor, apesar do elevado número de estudos ressaltando agravos à saúde docente. Métodos: O objetivo do estudo foi analisar publicações da Biblioteca Virtual de Saúde em Psicologia (BVS-Psi) dos últimos 14 anos (2003-2016) relacionadas à saúde no trabalho docente. Utilizaram-se os seguintes descritores: saúde professor, saúde docente, sofrimento professor, sofrimento docente, prazer professor, prazer docente, trabalho professor, trabalho docente, subjetividade professor, subjetividade docente, resultando em 69 artigos analisados. Resultados: Houve predomínio de publicações nas áreas de fonoaudiologia e psicologia, sendo a maior parte das pesquisas qualitativas. Os estudos evidenciaram o adoecimento docente na atualidade, apontando a necessidade de desenvolvimento de ações referentes à reorganização do trabalho docente e promoção de saúde do professor. Conclusão: Constatou-se a importância de privilegiar a multideterminação do processo de saúde-doença no trabalho docente, as compreensões interdisciplinares sobre o tema e a articulação entre as pesquisas e a realidade de trabalho dos professores para que se possa desenvolver metodologias e políticas públicas voltadas ao aprimoramento da saúde docente.
\end{abstract}

Palavras-chave: saúde docente; saúde professor; saúde coletiva; trabalho.

\section{Abstract}

Introduction: The health of teachers appears as a current concern. The number of teachers getting sick at work is growing, however few measures are being taken in terms of specific legislation and policies that favor teacher health. This is despite the large number of studies highlighting harm to health of teachers. Methods: The objective of the study was to analyze the publications in Virtual Health Library Psychology (BVS-Psi) over the last 14 years (2003-2016) related to the health of teachers. We used descriptors in Portuguese language related to health in elementary school teachers and university professors, which resulted in 69 articles analyzed. Results: Publications were predominantly in the areas of speech therapy and psychology using qualitative methodology. The studies have shown teacher's illness as a current problem, pointing to the need to develope strategies related to the reorganization of teacher working conditions and health promotion. Conclusion: The importance of emphasizing the multidimensionality of health and disease related to teacher's work was noted, highlighting interdisciplinary understandings of the topic. Also, the need for more integration of research and the work reality of teachers was noted, if we intended to develop methodologies and policies aimed at improving teacher health.

Keywords: faculty health; teacher health; public health; work. 


\section{INTRODUÇÃO}

A saúde do trabalhador é um campo interdisciplinar articulado com movimentos sociais que surgiu por meio de críticas às limitações dos modelos sociais e políticos vigentes em sua época. Nesse sentido, como parte da saúde coletiva, constitui-se como espaço interdisciplinar e pluri-institucional que apreende o trabalho como um dos principais determinantes sociais da saúde ${ }^{1}$. Por essa razão, a saúde do trabalhador segue em um caminho favorável ao empoderamento dos trabalhadores, valorizando o bem-estar do sujeito em detrimento das práticas organizacionais, o que muitas vezes resulta em embates teóricos quanto à possibilidade do pleno exercício de suas proposições ${ }^{2}$.

Segundo Minayo-Gomez et al. ${ }^{3}$, o aspecto norteador da saúde do trabalhador consiste na abordagem dos problemas de forma processual no que tange aos elementos sociais e políticos, compreendendo as contradições existentes nas organizações como um possível espaço de atuação para a promoção da saúde coletiva. Para Menezes ${ }^{4}$, a saúde do trabalhador busca relacionar as dinâmicas existentes nas organizações de trabalho com seu caráter histórico e social para então compreender a determinação dos fenômenos, demarcando uma nova corrente de pensamento que enfatiza a dimensão histórico-cultural na constituição humana, a qual integra os aspectos biológicos e psicológicos ao contexto social em que são produzidos.

Especificamente sobre a subjetividade no trabalho, encontram-se nas elaborações de Dejours et al. ${ }^{5}$, relativas à psicodinâmica do trabalho, a associação entre organização, forças produtivas, aspectos psicológicos e elementos sociais do trabalho. Em seus escritos, Dejours et al. ${ }^{5}$ buscavam primordialmente compreender de que maneira os trabalhadores mantinham certo equilíbrio psíquico, ainda que submetidos às condições de trabalho degradantes que resultavam em intenso sofrimento e adoecimento. Segundo Dejours ${ }^{6}$, o sofrimento psíquico teria origem na mecanização e robotização das tarefas que se expressam por meio de um fazer ausente de sentido, determinado, a priori, pela lógica de administração científica do trabalho. Assim, as pressões e imposições exercidas pelas organizações de trabalho, associadas às exigências de adaptação à cultura e valores organizacionais, levariam o trabalhador ao sofrimento e exaustão para atender à sobrecarga de trabalho própria do modelo administrado de trabalho ${ }^{7}$

Na educação é possível verificar esse processo por meio do histórico de desenvolvimento das políticas públicas. Segundo Assunção et al. ${ }^{8}$, as políticas públicas educacionais do Brasil são movidas por valores de universalização, desde o início da década de 1990, às custas da precarização do sistema educacional e da intensificação do trabalho docente. Para Brant et al. ${ }^{9}$, isso acontece pois há a necessidade de satisfazer a clientela com a proposição de que a educação é acessível para todos no país, mas poucas considerações são feitas a respeito dos impactos desse processo naqueles que trabalham nas redes educacionais e na qualidade do serviço prestado pelos docentes nas redes de ensino do país.

Especificamente sobre o reflexo desse processo na saúde do trabalhador, verificam-se diversos estudos relacionados ao adoecimento docente ${ }^{10,11} \mathrm{e}$ ao sofrimento psíquico ${ }^{12-15}$. Diante dessa realidade, Araújo et al. ${ }^{11}$ destacam a necessidade de compreender o campo da saúde do trabalhador relacionado ao trabalho docente como uma forma de contribuir na produção de melhorias nas condições de trabalho dos professores e, consequentemente, no desenvolvimento da saúde coletiva nacional. A partir dessa proposição e considerando que, apesar do elevado número de produções, não existem levantamentos da literatura que versem sobre o tema nos últimos 12 anos, propôs-se o estudo em questão.

\section{MÉTODO}

O objetivo geral do trabalho foi verificar na literatura nacional as produções relacionadas à saúde no trabalho docente, a fim de descrever e sintetizar as evidências apontadas pelos estudos. Para tanto, realizou-se um levantamento, tendo como modalidade textual artigos científicos, dos estudos disponíveis na Biblioteca Virtual de Saúde em Psicologia (BVS-Psi) entre os anos de 2003 e 2016 e indexados pelas bases de dados SciELO Brasil (Scientific Eletronic Library Online) e PePSIC (Períodicos Eletrônicos em Psicologia). A escolha das bases de dados justifica-se pelo interesse dos pesquisadores em apreender prioritariamente aspectos psicossociais relacionados à saúde no trabalho docente no campo da saúde coletiva. Já a opção pelos artigos científicos como modalidade textual, justifica-se pela compreensão dos autores de que as teses e dissertações com maior impacto em suas áreas são divulgadas nesse formato.

Para a busca dos trabalhos, utilizaram-se os descritores considerados representativos à temática investigada, os quais foram empregados isoladamente e em associação, tais como: saúde professor, saúde docente, sofrimento professor, sofrimento docente, prazer professor, prazer docente, trabalho professor, trabalho docente, subjetividade professor, subjetividade docente. O resultado preliminar da busca resultou em 1694 trabalhos para a triagem, dos quais tiveram 426 selecionados, tendo como critério a adequação do título ao tema investigado e a exclusão de ocorrências duplicadas. Desses 426 trabalhos, iniciou-se a inspeção por meio da leitura dos resumos, o que resultou na exclusão de 357 inadequados ao tema proposto para essa investigação. Assim, alcançou-se o total de 69 trabalhos elegíveis para a análise, os quais foram lidos na íntegra e incluídos neste estudo. O procedimento de triagem, inspeção e elegibilidade dos artigos para análise é representado graficamente abaixo por meio da Figura 1. 
Ressalta-se que, para avaliar a fidedignidade do levantamento realizado, a busca foi feita por dois pesquisadores de forma independente, obtendo-se uma convergência entre os resultados encontrados por eles em 89\%. Ademais, na apresentação dos resultados utilizou-se da técnica de análise de conteúdo ${ }^{16}$ para categorização dos descritores em eixos temáticos, a fim de facilitar a descrição e síntese das informações levantadas por meio do estudo.

\section{RESULTADOS}

\section{Formação acadêmica dos autores, referencial teórico e} tema dos estudos

O desenvolvimento das investigações foi realizado em sua maioria por profissionais da área de fonoaudiologia (vinte e um), psicologia (quinze), pedagogia (dez), medicina (cinco), educação física (cinco), administração (três), enfermagem (três), letras (dois) e terapia ocupacional (dois). Houve ainda um representante das seguintes áreas: estatística, fisioterapia e ciências biológicas.
A maior parte dos autores adotou como referencial teórico uma perspectiva sociointeracionista (cinquenta e quatro), em que a relação entre o sujeito e o contexto de trabalho é determinante para a compreensão das dinâmicas referentes à saúde e qualidade de vida do trabalhador. Nos demais estudos, prevaleceram como referencial a psicodinâmica do trabalho (treze), ressaltando aspectos da subjetividade existente na relação entre sujeito e trabalho. Dois trabalhos utilizaram documentos legislativos, fazendo uso de diretrizes legais como referencial para análise. Em relação aos temas, os principais pontos abordados pelas pesquisas foram: qualidade de vida e saúde física e vocal do professor (vinte e dois), precarização das condições de trabalho, estresse, ruído (quinze), subjetividade e trabalho (treze), adoecimento físico, vocal, mental e dor (oito), promoção de saúde nas escolas (cinco), poder público e políticas públicas (três) e Síndrome de Burnout (três). Os elementos fundantes e teóricos das investigações são sintetizados na Tabela 1 a seguir:

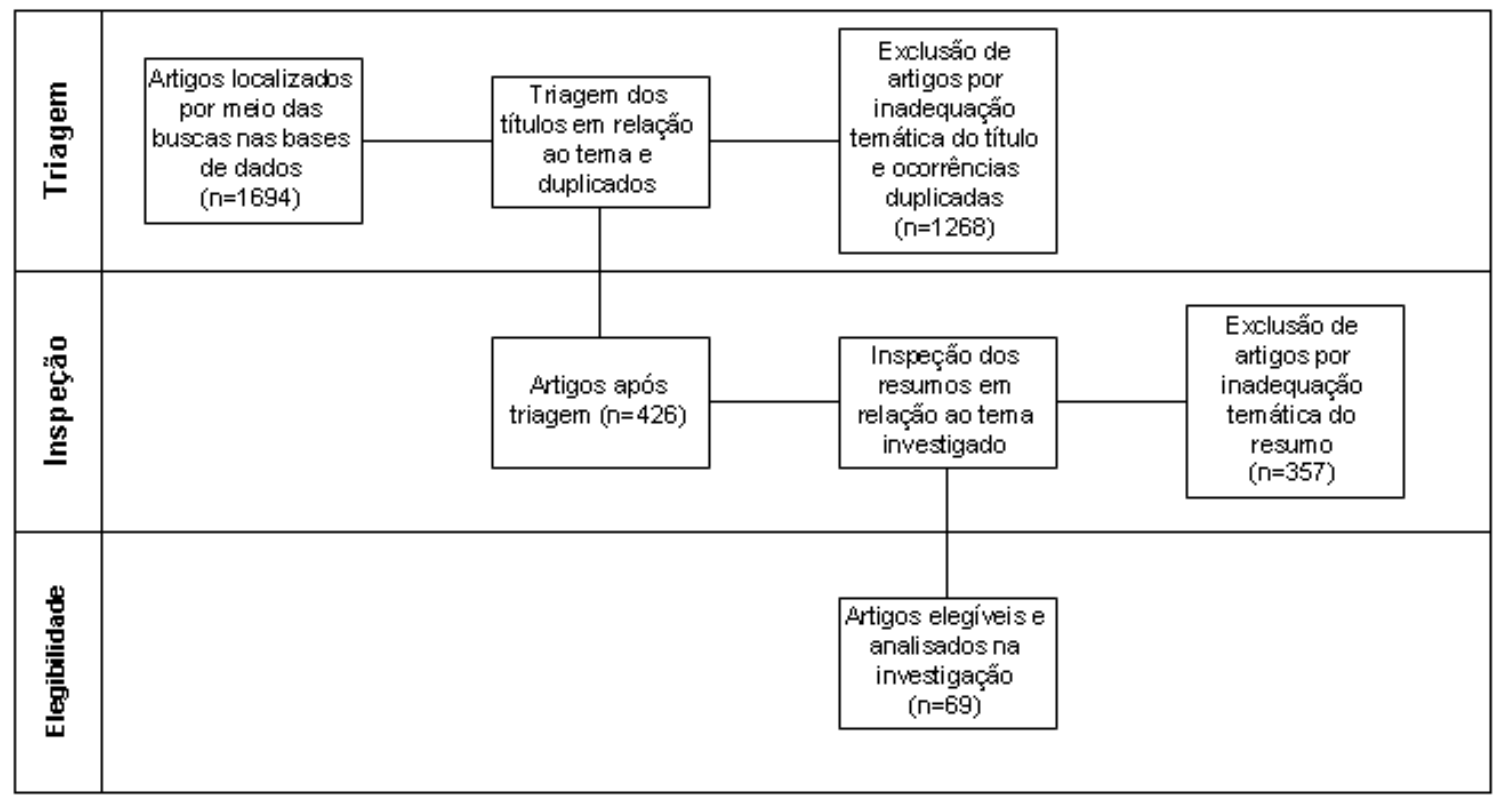

Figura 1. Descrição do procedimento de triagem, inspeção e elegibilidade dos estudos analisados

Tabela 1. Descrição dos aspectos fundantes e teóricos das investigações

\begin{tabular}{lclcl} 
& \multicolumn{3}{c}{ Área } & \multicolumn{2}{c}{ Referencial teórico } & \multicolumn{2}{c}{ Tema } \\
Fonoaudiologia & 21 & Sociointeracionismo & 54 & Qualidade de vida e saúde \\
Psicologia & 15 & Psicodinâmica do trabalho & 13 & Precarização, estresse e ruído \\
Pedagogia & 10 & Documentos e legislações & 2 & Subjetividade e trabalho \\
Medicina & 5 & & Adoecimento e dor & 15 \\
Educação Física & 5 & & Promoção de saúde \\
Administração & 3 & & Políticas públicas \\
Enfermagem & 3 & Síndrome de Burnout & \\
Letras & 2 & & & \\
Terapia Ocupacional & 2 & & & \\
Outras & 3 & & & 3 \\
\hline
\end{tabular}




\section{Objetivos propostos pelos estudos}

Entre os objetivos propostos pelas investigações, verificaram-se: a) compreender a relação entre contexto de trabalho, qualidade de vida e adoecimento docente (vinte e três); b) verificar a relação entre sintomas vocais, estresse e adoecimento docente (dezoito); c) analisar o sentido atribuído ao trabalho e à saúde pelo professor (nove); d) verificar a percepção dos professores sobre práticas de atenção primária e promoção de saúde nas escolas (nove); e) examinar o papel do poder público e legislações específicas na proteção à saúde do professor (cinco) e mensurar os níveis de saúde física e mental do professor (cinco).

\section{Participantes e objetos das investigações}

Houve predomínio da participação de professores nos estudos, apesar de não ser consensual entre os autores o critério para classificação dos participantes. Os pesquisadores oscilaram entre descrever a amostra a partir do local de trabalho ou nível de ensino em que os participantes atuavam. Nesse sentido, foram obtidas as seguintes descrições: professores de rede pública de ensino (quinze); professores de ensino fundamental e médio (doze); professores de ensino superior (doze); artigos, teses e dissertações sobre o tema (sete); legislações, prontuários e diários de campo (sete); professores de academia de ginástica (dois); professores de educação infantil (dois). Houve ainda a ocorrência do termo professor de forma genérica sem maiores especificações (doze).

\section{Metodologia empregada e instrumento de coleta de dados}

A maior parte dos estudos apresentou, na condução das investigações, metodologia qualitativa (vinte e seis), seguida de metodologia quantitativa (vinte e cinco) e multimétodo (doze). Houve também, em menor ocorrência, o uso da metodologia etnográfica (três) e estudos teóricos ou de revisão de literatura (três). Quanto ao tipo de coleta de dados, verificou-se a prevalência de questionários (dezessete), análise de registros, diários de campo ou documentos (dezesseis), entrevistas (onze), observação participante (dois) e grupo focal (dois). Os demais estudos utilizaram técnicas mistas, como: questionário, gravação da voz e avaliação clínica ou técnica projetiva (dez); entrevista seguida de aplicação de questionário (três); gravação de voz, avaliação clínica e entrevista ou grupo focal (três); entrevista e observação participante ou grupo (três) e questionário e grupo focal (dois). Os principais aspectos metodológicos dos estudos são descritos na Tabela 2.

\section{Evidências apontadas pelos estudos}

Os resultados dos artigos foram organizados em sete categorias com maior ocorrência entre as investigações encontradas na literatura, sendo elas: aspectos contextuais do trabalho docente (treze), sintomas físicos (onze), sintomas psíquicos (doze), promoção de saúde (dezesseis), políticas públicas e organização do trabalho (doze), análise das legislações trabalhistas (dois) e aspectos teóricos-metodológicos (três). A categoria aspectos contextuais do trabalho docente agrupou estudos sobre a dupla jornada, excesso de tarefas e dificuldades de relacionamento entre família-escola ${ }^{17}$, aumento da carga de trabalho ${ }^{8}$, demanda por índices institucionais elevados ${ }^{18,19}$, alta pressão por desempenho e baixo nível de controle das tarefas ${ }^{20}$, desordem em sala de aula ${ }^{21}$, ruídos $^{22,23}$, hostilidade entre alunos ${ }^{24}$, desvalorização pessoal e salarial ${ }^{25,26}$, problemas institucionais ${ }^{27}$ e baixa remuneração, excesso de alunos em sala e infraestrutura escolar inadequada para o trabalho ${ }^{28}$.

Já os sintomas físicos evidenciados nos estudos foram dores corporais e agravos à saúde decorrentes do envelhecimento ${ }^{29,30}$, perda auditiva e problemas nas cordas vocais ${ }^{31-34}$, disfonia ${ }^{35-37}$, dores nos membros superiores e dorso relativas ao esforço excessivo ${ }^{38} \mathrm{e}$ incoordenação pneumofônica ${ }^{39}$. Quanto aos sintomas psíquicos, prevaleceram regressão ${ }^{40}$, exaustão emocional, nervosismo, estresse e insônia ${ }^{41}$, Síndrome de Burnout ${ }^{42-44}$, transtornos psíquicos e afastamentos do trabalho ${ }^{45,46}$, prejuízos na criatividade e domínios socioemocionais ${ }^{47,48}$, negação ${ }^{49}$, despersonalização ${ }^{50}$ e distorções na percepção da importância e do esforço dedicado ao trabalho - o trabalho como um "sacerdócio" - que predispõe o docente a se submeter a riscos e sobrecarga ${ }^{51}$.

Entre as práticas e medidas de promoção de saúde, os estudos mostraram que: favorecer a ética, a autonomia e a preocupação coletiva no trabalho diminuem o estresse ocupacional ${ }^{52}$; a articulação entre pesquisa e trabalho docente favorece a otimização das condições de trabalho pelo professor ${ }^{53}$; a orientação e diagnóstico fonoaudiológico aprimora o cuidado com a própria voz e reduz a exposição ao risco no ambiente de

Tabela 2. Descrição dos objetos, participantes e elementos metodológicos

\begin{tabular}{lclcll}
\multicolumn{1}{c}{ Participantes } & & & & & \multicolumn{2}{c}{ Método } & & \\
Rede pública & 15 & Qualitativo & 26 & Questionários & 17 \\
Ensino fundamental e médio & 12 & Quantitativo & 25 & Registros escritos & 16 \\
Ensino superior & 12 & Multimétodo & 12 & Entrevistas & 11 \\
Não especificado & 12 & Etnográfico & 3 & Observação & 2 \\
Academias & 2 & Teórico & 3 & Grupos & Técnicas mistas \\
Educação infantil & 2 & & & & \\
Artigos e teses & 7 & & & & \\
Leis e registros & 7 & & & & \\
\hline
\end{tabular}


trabalho ${ }^{54-56}$; os treinos e aquecimentos vocais, bem como as oficinas fonoaudiológicas diminuem os problemas vocais ${ }^{57-59}$; as intervenções dialógicas em grupo que articulam o saber técnico-profissional com especificidades contextuais apresentam maior eficácia na mudança de hábitos ${ }^{60-62}$; as oportunidades de lazer, melhores condições de trabalho e econômicas, bem como acesso à orientação em saúde vocal protegem agravos à voz do professor ${ }^{63,64}$; a discussão de ideais e utopias políticas e educacionais com professores favorecem a resistência às dificuldades cotidianas ${ }^{65}$ e a possibilidade de se vivenciar qualidade de vida, apesar da presença do adoecimento, desde que sejam desenvolvidos mecanismos de suporte social no trabalho ${ }^{66}$ e ampliada a compreensão da noção de saúde por parte dos docentes ${ }^{67}$.

Na categoria políticas públicas e organização do trabalho, foram marcantes alguns pontos, como: a atribuição, pelos professores, a terceiros (administração escolar, governo e profissionais de saúde) como responsáveis pela promoção de saúde ${ }^{68,69}$; perpetuação do assistencialismo e desconhecimento de políticas públicas pelos educadores ${ }^{70}$; dificuldade dos docentes para atender alunos com deficiência e outras políticas inclusivas pela falta de dispositivos de apoio e treinamento específico ${ }^{71,72}$; excesso de trabalho em casa $^{73}$; ênfase excessiva às diretrizes curriculares e profissionalizantes em detrimento das percepções dos professores ${ }^{74}$; papel do Estado como regulador do desempenho docente $e^{75}$; limitação da lógica de administração gerencial para regular o trabalho docente ${ }^{76}$; desconsideração das necessidades afetivas e subjetivas dos professores ${ }^{77}$; ausência de incentivo para a qualificação e atualização profissional ${ }^{78}$ e a inadequação da acepção comum de trabalho para compreender e administrar a prática profissional e formativa exercida pelo docente ${ }^{79}$.

Sobre a análise das legislações trabalhistas, verificaram-se poucos documentos que explicitassem fatores relacionados à organização do trabalho docente. Entre os agentes ambientais nocivos no trabalho do professor, o ruído, a poeira, a temperatura e a iluminação inadequada foram listados ${ }^{80}$. Nas legislações estaduais, majoritariamente concentradas na região sudeste, houve maior ênfase no modelo curativo em detrimento da promoção de saúde ${ }^{81}$. Por último, quanto aos aspectos teóricos-metodológicos, as produções da área foram predominantemente descritivas e realizadas por grupos de pesquisas entre o período de 1987 e $2003^{82}$. Já as publicações mais recentes apresentaram baixa padronização dos instrumentos e protocolos de avaliação para a triagem e formulação de estratégias de intervenção, as quais se restringem à avaliação vocal ${ }^{83,84}$. Na Tabela 3 , os resultados são agrupados por meio de eixos comuns, em relação à temática, e

Tabela 3. Análise de conteúdo dos estudos levantados

Eixos de análise

Promoção de saúde

Favorecer ética, autonomia, coletividade, suporte social e articulação entre pesquisa e trabalho, orientação, treinos, aquecimentos e oficinas fonoaudiológicas

Diálogos em grupo e valorização do saber cotidiano

Melhores oportunidades de lazer, trabalho e econômicas

Discussão de ideais e utopias políticas e educacionais, ampliar concepção de saúde

Dupla jornada, excesso e sobrecarga de trabalho, demanda elevada, pressão, baixo controle do trabalho, indicadores

Desordem, ruído, hostilidade, desvalorização pessoal e salarial

Problemas institucionais, excesso de alunos e infraestrutura inadequada

Regressão, negação, despersonalização, distorções perceptivas

Sintomas psíquicos

Síndrome de Burnout, exaustão emocional, nervosismo, estresse e insônia

Transtornos psíquicos e afastamento

Prejuízos na criatividade e domínios emocionais

Atribuição da responsabilidade a terceiros e o papel regulador do Estado

Assistencialismo e desconhecimento de políticas públicas

Dificuldade de atendimento aos alunos com deficiência, falta de apoio e treinamento específico,

Políticas públicas e organização

ausência de incentivo para qualificação

Excesso de trabalho em casa, limitação do modelo administrativo clássico para regular o trabalho

docente, inadequação da noção comum de trabalho para compreender a prática docente

Ênfase nas diretrizes curriculares e desconsideração da opinião do professor e suas necessidades afetivas e subjetivas

Dores corporais e envelhecimento

Sintomas físicos

Perda auditiva, problemas vocais, disfonia, incoordenação pneumofônica

$11 \quad 16 \%$ Dores nos membros superiores e dorso por esforço excessivo

\begin{tabular}{|c|c|c|c|}
\hline $\begin{array}{l}\text { Aspectos teóricos e } \\
\text { metodológicos }\end{array}$ & $\begin{array}{l}\text { Predominância descritiva e grupos de pesquisa } \\
\text { Baixa padronização de instrumentos e protocolos para triagem e intervenção }\end{array}$ & 3 & $4 \%$ \\
\hline Legislações & $\begin{array}{l}\text { Lacunas sobre os agentes ambientais nocivos (poeira, temperatura e iluminação), ênfase na } \\
\text { região sudeste e na esfera estadual } \\
\text { Valorização do modelo curativo em vez de ações de promoção de saúde }\end{array}$ & 2 & $3 \%$ \\
\hline & $\mathbf{n}$ & 69 & $100 \%$ \\
\hline
\end{tabular}


descritos, em frequência, a partir da quantidade de ocorrência temática.

\section{DISCUSSÃO}

Considerando-se os estudos levantados, nota-se maior contribuição da fonoaudiologia na elaboração de estratégias de prevenção e promoção de saúde quando comparada às outras áreas, as quais dão maior ênfase à compreensão das condições de trabalho e outros aspectos relacionados à saúde no trabalho docente. Apreende-se ainda que a predominância das contribuições de autores da fonoaudiologia e psicologia influencia os principais aportes teóricos encontrados, tendo em vista que tanto a perspectiva sociointeracionista, quanto a psicodinâmica do trabalho associam-se, respectivamente, a essas áreas.

A maior ocorrência da perspectiva sociointeracionista ${ }^{2,3}$ demonstra que os estudos buscam articular os achados sobre a saúde docente ao meio em que são produzidos, compreendendo a saúde do trabalhador como um processo biopsicossocial. Já a presença da psicodinâmica do trabalho $0^{5,6}$ parece apontar a preocupação dos pesquisadores em compreender a implicação da subjetividade na constituição do processo de saúde-doença vivenciado pelos professores. Essa preocupação e articulação entre saúde, subjetividade e contexto-social é evidenciada ainda pelos principais objetivos dos estudos, os quais articulam ambiente de trabalho, adoecimento, sintomas vocais e estresse com fatores mais amplos, como a qualidade de vida ${ }^{47,50,63,83}, \mathrm{o}$ que permite inferir o quanto o trabalho é compreendido nas investigações como um dos determinantes sociais do processo de saúde-doença.

Em relação aos participantes da amostra, houve predominância de pesquisas entre professores do ensino básico de redes públicas, sendo possível notar também a presença de estudos sobre a saúde docente no ensino superior. Pelos apontamentos dos estudos, é possível ainda inferir que a massificação e precarização das condições de saúde e trabalho na educação é abrangente, incidindo nos diversos níveis de escolarização, e impacta de forma semelhante a saúde do trabalhador docente nos diferentes níveis de ensino ${ }^{18,19,25,26,30}$. Nota-se ainda no aspecto teórico-metodológico razoável equilíbrio entre a metodologia quantitativa e qualitativa, com a presença de técnicas descritivas, inferenciais e estudos de caso, que evidenciam as múltiplas formas de compreender a saúde no trabalho docente. Essa multiplicidade teórico-metodológica permite a construção de uma diversidade de hipóteses explicativas sobre o fenômeno, mas também revela que a agenda de pesquisa da área pode ser aprimorada do ponto de vista metodológico. No levantamento, nota-se que as contribuições mais significativas surgem dos estudos multimétodos que aplicaram técnicas mistas para a coleta dos dados, o que pode indicar um percurso metodológico a ser seguido nos estudos futuros ${ }^{32,33,51}$.
Além disso, observando-se a Tabela 3, verifica-se que os estudos não contribuem na proposição de mecanismos capazes de gerar transformações concretas no contexto do trabalho docente. Foram predominantes entre as pesquisas do levantamento os eixos de promoção de saúde, aspectos contextuais, sintomas psíquicos, políticas públicas e organização do trabalho e sintomas físicos, o que sugere que a área abrange uma pluralidade de temas ao mapear os determinantes psicossociais da saúde coletiva no trabalho docente, mas não consegue articulá-los de forma ótima para a proposição de políticas e práticas concretas.

Essa falha na geração de estudos que substanciem o desenvolvimento de protocolos e estratégias, para o enfrentamento e tratamento da saúde coletiva dos professores, torna-se ainda mais evidente ao se observar as políticas públicas sobre o tema, as quais ainda são pouco impactadas por iniciativas e estratégias desenvolvidas por contribuições científicas, estando, a maior parte delas, estabelecidas de forma lacunar e concentradas na região sudeste ${ }^{81,83,84}$. Em uma perspectiva geral, os estudos mais recentes parecem ter mantido a predominância descritiva e pouco avançaram no desenvolvimento de metodologias mais efetivas que promovam impactos concretos na saúde coletiva dos professores, tal como evidenciado em revisão anterior sobre o tema por volta do ano $2000^{82}$.

Assim, enquanto os estudos não avançam em uma agenda que aprimore as políticas públicas e legislações sobre o tema, permanece a reprodução do contexto de precarização e intensificação do trabalho docente iniciado em $1990^{8}$, ao passo que a literatura sobre o tema se mantém, majoritariamente, apenas descrevendo os determinantes psicossociais da saúde no trabalho docente e apontando a existência de sofrimento e adoecimento no contexto de atuação dos professores. Sobre esse ponto, pode facilitar aos pesquisadores da área, na integração das pesquisas às práticas concretas, associar as necessidades teóricas do campo à implicação de seus estudos, por meio de respostas a aspectos balizadores da investigação como: "1) de que forma a investigação em questão facilita a proposição de metodologias e protocolos de intervenção na saúde coletiva para o otimizar o trabalho docente?" e "2) como os determinantes psicossociais identificados no estudo podem contribuir e impactar a elaboração de políticas públicas sobre o tema?”

Ademais, existe ainda uma lacuna entre a concepção teórica dos estudos e o desenvolvimento das investigações, uma vez que a maioria dos autores compreende os elementos relacionados à saúde no trabalho do professor de forma multideterminada, mas restringe os tópicos das pesquisas à sua própria área de investigação. Nesse sentido, sugere-se que investigações futuras façam uso da interdisciplinaridade ao versar sobre o tema, pois somente por meio de uma agenda de pesquisa fundamentada na interdisciplinaridade e na implicação empírica dos estudos será possível desenvolver metodologias e contribuições capazes de fundamentar o desenvolvimento de políticas públicas relativas à saúde no trabalho docente ${ }^{60}$. 


\section{CONCLUSÕES}

Entre as limitações do presente levantamento destaca-se que, por se tratar de um estudo descritivo, ele não foi capaz de avaliar a heterogeneidade das metodologias empregadas, as quais devem ser consideradas pelos pesquisadores que buscarem comparar quantitativamente os efeitos das variáveis relacionadas à saúde dos professores. Além disso, pela base de dados empregada ter como foco específico a psicologia e áreas correlatas, os resultados encontrados não podem ser generalizados para um estado da arte das produções em saúde no trabalho docente em um sentido mais amplo. Dessa forma, recomenda-se que estudos de revisão futuros deverão enfatizar aspectos quantitativos, preferencialmente meta-analíticos, filtrando as variáveis de interesse e seus respectivos efeitos, conforme a ênfase da investigação.

As evidências encontradas também parecem apontar maior necessidade de estudos sobre a saúde no trabalho docente na educação infantil, redes particulares de ensino, espaços de educação não formais (organizações não governamentais e terceiro setor) e nas novas formas e tecnologias de ensino e comunicação, tais como o ensino à distância (EAD) que não foram abordados de forma abrangente entre os estudos levantados. Outro ponto elementar refere-se à ausência de estudos que teçam considerações a respeito do impacto que elementos contextuais - como o substrato econômico e político num momento de instabilidade e restrição orçamentária - podem desencadear no financiamento de ações, políticas e legislações que fomentem a promoção de saúde no trabalho docente, o que deve integrar a agenda de pesquisa da área.

Por fim, considerando-se um retrato geral da saúde no trabalho docente, é possível inferir o seguinte quadro: a intensificação da jornada de trabalho ${ }^{8,19} \mathrm{e}$ a desarticulação das políticas ${ }^{70}$ que legislam sobre o tema perpetuam a construção de um ciclo de adoecimento físico e mental ${ }^{10}$ que implica sofrimento, desestruturação psíquica e problemas vocais aos professores ${ }^{20}$. Espera-se, por meio da síntese gerada no presente estudo, reafirmar a necessidade de pesquisas sobre o tema capazes de produzir conhecimento para o aprimoramento das condições de saúde dos professores de forma geral. Afinal, pelos elementos apresentados nos estudos levantados, há indícios de que o adoecimento físico e mental dos professores decorre de condições de administração do trabalho ${ }^{79}$ e promoção de saúde ${ }^{67}$ insatisfatórias no contexto atual e apresentam-se como questões relevantes no âmbito da saúde coletiva.

\section{REFERÊNCIAS}

1. Costa DM, Lacaz FAC, Jackson Fo JM, Vilela RAG. Saúde do trabalhador no SUS: desafios para uma política pública. Rev Bras Saúde Ocup. 2013;38(127):11-30. PMid: 03037657. http://dx.doi.org/10.1590/S030376572013000100003

2. Mendes R, Dias EC. Da medicina do trabalho à saúde do trabalhador. Rev Saude Publica. 1991;25(5):341-9. PMid:1820622. http://dx.doi.org/10.1590/ S0034-89101991000500003.

3. Minayo-Gomez C, Thedim-Costa SM. A construção do campo da saúde do trabalhador: percurso e dilemas. Cad Saude Publica. 1997;13(2 Suppl):21-32. PMid:10886935. http://dx.doi.org/10.1590/S0102-311X1997000600003.

4. Menezes LS. Um olhar psicanalítico sobre a precarização do trabalho: desamparo, pulsão de domínio e servidão [tese]. São Paulo: Universidade de São Paulo; 2010

5. Dejours C, Abdoucheli E, Jayet C. Psicodinâmica do trabalho. São Paulo: Atlas; 1994.125 p.

6. Dejours C. O fator humano. Rio de Janeiro: Fundação Getúlio Vargas; 1997.

7. Ferreira MC, Mendes AM. "Só de pensar em vir trabalhar, já fico de mau humor": atividade de atendimento ao público e prazer-sofrimento no trabalho. Estud Psicol. 2001;6(1):93-104. PMid: 16784669. http://dx.doi. org/10.1590/S1413-294X2001000100010.

8. Assunção AA, Oliveira DA. Intensificação do trabalho e saúde dos professores. Educ Soc. 2009;30(107):349-72. PMid: 01017330. http://dx.doi.org/10.1590/ S0101-73302009000200003.

9. Brant LC, Minayo-Gomez C. A transformação do sofrimento em adoecimento: do nascimento da clínica à psicodinâmica do trabalho. Cien
Saude Colet. 2004;9(1):213-23. PMid: 14138123. http://dx.doi.org/10.1590/ S1413-81232004000100021.

10. Reis EJFB, Carvalho FM, Araújo TM, Porto LA, Silvany No AM. Trabalho e distúrbios psíquicos em professores da rede municipal de Vitória da Conquista, Bahia, Brasil. Cad Saude Publica. 2005;21(5):1480-90. PMid:16158154. http://dx.doi.org/10.1590/S0102-311X2005000500021.

11. Araújo TM, Reis E, Kavalkievicz C, Silvany No A, Paranho I, Carvalho F, et al. Saúde e trabalho docente: dando visibilidade aos processos de desgaste e adoecimento docente a partir da construção de uma rede de produção coletiva. Educ Rev. 2003;37:183-212.

12. Macêdo KB. O trabalho de quem faz arte e diverte os outros. Goiânia: Pontifícia Universidade Católica de Goiás; 2010.

13. Souza LK. As vivências dos designers de moda em relação ao seu trabalho: uma abordagem Psicodinâmica [tese]. Goiânia: Pontifícia Universidade Católica de Goiás; 2010.

14. Ferreira JB. O poder constituinte do trabalho vivo: análise psicodinâmica da criação literária [tese]. Brasília: Universidade de Brasília; 2011.

15. Merlo ARC, Mendes AMB. Perspectivas do uso da psicodinâmica do trabalho no Brasil: teoria, pesquisa e ação. Cad Psicol Soc Trab. 2009;12(2):141-56. PMid: 15163717. http://dx.doi.org/10.11606/issn.1981-0490.v12i2p141-156.

16. Bardin L, Reto LA, Pinheiro A. Análise de conteúdo. Lisboa: Edições 70; 1979.

17. Valle LER, Reimão R, Malvezzi S. Reflexões sobre Psicopedagogia, estresse e distúrbios do sono do professor. Rev Psicopedagogia. 2011;28(87):237-45. PMid: 01038486. Disponível em: http://pepsic.bvsalud.org/pdf/psicoped/ v28n87/04.pdf. 
18. Cassandre MP. A saúde de docentes de pós-graduação em universidades públicas: os danos causados pelas imposições do processo avaliativo. Rev Mal-Estar Subj. 2011;11(2):779-816. PMid 15186148. Disponível em: http://pepsic.bvsalud.org/pdf/malestar/v11n2/13.pdf.

19. Sampaio PP, Caldas JMP, Catrib AMFA. (des)estabilização das redes sociais e o impacto na saúde do professor universitário: o caso português. Cad Saude Colet. 2015;23(3):239-44. PMid 1414462X. http://dx.doi.org/10.1590/1414$462 X 201500030114$.

20. Giannini SPP, Latorre MRDO, Ferreira LP. Distúrbio de voz e estresse no trabalho docente: um estudo caso-controle. Cad Saude Publica. 2012;28(11):2115-24. PMid:23147953. http://dx.doi.org/10.1590/S0102311X2012001100011.

21. Iaochite RT, Azzi DRG, Polydoro DSAJ, Winterstein DPJ. Autoeficácia docente, satisfação e disposição para continuar na docência por professores de Educação Física. Rev Bras Ciênc Esporte. 2011;33(4):825-39. PMid: 01013289. http://dx.doi.org/10.1590/S0101-32892011000400003.

22. Servilha EAM, Delatti MA. Percepção do ruído no ambiente de trabalho e sintomas auditivos e extra-auditivos autorreferidos por professores universitários. J Soc Bras Fonoaudiol. 2012;24(3):233-8. PMid:23128171. http://dx.doi.org/10.1590/S2179-64912012000300008.

23. Palma A, Mattos UAO, Almeida MNOG, Oliveira GE. Nível de ruído no ambiente de trabalho do professor de educação física em aulas de ciclismo indoor. Rev Saude Publica. 2009;43(2):345-51. PMid:19287876. http:// dx.doi.org/10.1590/S0034-89102009000200016.

24. Noronha MMB, Assunção AA, Oliveira DA. O sofrimento no trabalho docente: o caso das professoras da rede pública de Montes Claros, Minas Gerais. Trab Educ Saúde. 2008;6(1):65-85. PMid: 19817746. http://dx.doi. org/10.1590/S1981-77462008000100005.

25. Vilela EF, Garcia FC, Vieira A. Vivências de prazer-sofrimento no trabalho do professor universitário: estudo de caso em uma instituição pública. Rev Eletrôn Adm. 2011;19(2):517-40. PMid 14132311. http://dx.doi.org/10.1590/ S1413-23112013000200010.

26. Moraes RD. Prazer e sofrimento no trabalho docente: estudo com professoras de ensino fundamental em processo de formação superior. Rev Psicol. 2005 [citado em 2017 jan 1];5(1):159-83. PMid: 19846657. Disponível em: http:// pepsic.bvsalud.org/pdf/rpot/v5n1/v5n1a07.pdf.

27. Mendes L, Chaves CJA, Santos MC, Neto M, Ramos GA. Da arte ao ofício: vivências de sofrimento e significado do trabalho de professor universitário. Rev Mal-Estar Subj. 2007 [citado em 2017 jan 1];7(2):527-56. PMid: 21753644. Disponível em: http://pepsic.bvsalud.org/pdf/malestar/ v7n2/15.pdf.

28. Guerreiro NP, Nunes EFPA, González AD, Mesas AE. Perfil sociodemográfico, condições e cargas de trabalho de professores da rede estadual de ensino de um município da região sul do Brasil. Trab Educ Saúde. 2016;14(1 Suppl):197-217. PMid: 16781007. http://dx.doi.org/10.1590/1981-7746sol00027.

29. Lüdorf SMA, Ortega FJG. Marcas no corpo, cansaço e experiência: nuances do envelhecer como professor de Educação Física. Interface. 2013;17(46):66175. PMid: 18075762. http://dx.doi.org/10.1590/S1414-32832013005000019.

30. Mazon CCXE, Leite LP. O mal-estar docente em gestores escolares. Arq Bras Psicol. 2013 [citado em 2017 jan 1];65(20):304-18. PMid: 18095267. Disponível em: http://pepsic.bvsalud.org/pdf/arbp/v65n2/11.pdf.

31. Souza CL, Carvalho FM, Araújo TM, Reis EJFB, Lima VMC, Porto LA. Fatores associados a patologias de pregas vocais em professores. Rev Saude Publica. 2011;45(5):914-21. PMid:21829977. http://dx.doi.org/10.1590/ S0034-89102011005000055.
32. Ferreira LP, Giannini SPP, Alves NLL, Brito AF, Andrade BMR, Latorre MRDO. Distúrbio de voz e trabalho docente. Rev CEFAC. 2016;18(4):93240. PMid: 19820216. http://dx.doi.org/10.1590/1982-0216201618423915.

33. Cielo CA, Portalete CR, Ribeiro VV, Bastilha GR. Perfil vocal, ocupacional e de saúde geral de docentes de Santa Maria/RS. Rev CEFAC. 2016;18(3):63548. PMid: 19820216. http://dx.doi.org/10.1590/1982-021620161838515.

34. Ferracciu CCS, Santos DMT, Barros PX, Teixeira LR, Almeida MS. Índice de capacidade para o trabalho e desequilíbrio esforço-recompensa relacionado ao distúrbio de voz em professoras da rede estadual de Alagoas. Rev. CEFAC. 2015;17(5):1580-9. PMid: 15161846. http://dx.doi.org/10.1590/19820216201517517414 .

35. Luchesi KF, Mourão LF, Kitamura S, Nakamura HY. Problemas vocais no trabalho: prevenção na prática docente sob a óptica do professor. Saúde Soc. 2009;18(4):673-81. PMid: 19840470. http://dx.doi.org/10.1590/S010412902009000400011 .

36. Alves LP, Araújo LTR, Xavier Neto JA. A Prevalência de queixas vocais e estudo de fatores associados em uma amostra de professores de ensino fundamental em Maceió, Alagoas, Brasil. Rev Bras Saúde Ocup. 2010;35(121):168-75. PMid: 03037657. http://dx.doi.org/10.1590/S0303-76572010000100018.

37. Ceballos AGC, Carvalho FM, Araújo TM, Reis EJFB. Avaliação perceptivoauditiva e fatores associados à alteração vocal em professores. Rev Bras Epidemiol. 2011;14(2):285-95. PMid: 1415790X. http://dx.doi.org/10.1590/ S1415-790X2011000200010.

38. Cardoso JP, Ribeiro IQB, Araújo TM, Carvalho FM, Dos Reis EJFB. Prevalência de dor musculoesquelética em professores. Rev Bras Epidemiol. 2009;12(4):604-14. PMid: 1415790X. http://dx.doi.org/10.1590/S1415790X2009000400010.

39. Grillo M, Penteado RZ. Impacto da voz na qualidade de vida de professore(a) s do ensino fundamental. Pro Fono. 2005;17(3):311-20. PMid:16389788. http://dx.doi.org/10.1590/S0104-56872005000300006.

40. Bertão FR, Hashimoto F. Entre o desejo e o sofrimento psíquico no trabalho: um estudo de caso com professora de educação infantil. Psicol Rev. 2006 [citado em 2017 jan 1];12(20):141-63. PMid:16771168. Disponível em: http://pepsic.bvsalud.org/pdf/per/v12n20/v12n20a04.pdf.

41. Lima FEM, Lima-Filho DO. Condições de trabalho e saúde do/a professor/a universitário/a. Ciências \& Cognição. 2009 [citado em 2017 jan 1];14(3):6282. PMid:18084281. Disponível em: http://pepsic.bvsalud.org/pdf/epp/ v6n1/v6n1a08.pdf.

42. Silva MEP. Burnout: por que sofrem os professores? Estudos e Pesquisas em Psicologia. 2006;6(1):89-98. PMid: 1415790X. http://dx.doi.org/10.1590/ S1415-790X2010000300013.

43. Batista JBV, Carlotto MS, Coutinho AS, Augusto LGS. Prevalência da Síndrome de Burnout e fatores sociodemográficos e laborais em professores de escolas municipais da cidade de João Pessoa, PB. Rev Bras Epidemiol. 2010;13(3):502-12. PMid:20857036. http://dx.doi.org/10.1590/S1415790X2010000300013.

44. Silva NR, Bolsoni-Silva AT, Rodrigues OMPR, Capellini VLMF. O trabalho do professor, indicadores de Burnout, prátics educativas e comportamento dos alunos: correlação e predição. Rev Bras Educ Espec. 2015;21(3):363-76. PMid:14136538. http://dx.doi.org/10.1590/S1413-65382115000300004.

45. Gasparini SM, Barreto SM, Assunção AA. O professor, as condições de trabalho e os efeitos sobre sua saúde. Educ Pesqui. 2005;31(2):189-99. PMid:16784634. http://dx.doi.org/10.1590/S1517-97022005000200003.

46. Silva LA, Santos NIS. Subjetividade e trabalho na educação. Rev Mal-Estar Subj. 2011 [citado em 2017 jan 1];11(4):1429-60. PMid:15186148. Disponível em: http://pepsic.bvsalud.org/pdf/malestar/v1ln4/06.pdf. 
47. Jardim R, Barreto SM, Assunção AA. Condições de trabalho, qualidade de vida e disfonia entre docentes. Cad Saude Publica. 2007;23(10):2439-61. PMid:17891304. http://dx.doi.org/10.1590/S0102-311X2007001000019.

48. Vieira SRS. Sofrimento psíquico e trabalho. Rev Latinoam Psicopatol Fundam. 2014;17(1):114-24. PMid: 14154714. http://dx.doi.org/10.1590/ S1415-47142014000100009.

49. Santos MN, Marques AC. Condições de saúde, estilo de vida e características de trabalho de professores de uma cidade do sul do Brasil. Cien Saude Colet. 2013;18(3):837-46. PMid:23546210. http://dx.doi.org/10.1590/ S1413-81232013000300029.

50. Chalfin CM, Magro MLPD, Budde C. Entre o prazer e o sofrimento: um estudo sobre os sentidos do trabalho para professores universitários. Psicol Teor Prat. 2011;13(2):154-67. PMid:15163687. Disponível em: http://pepsic. bvsalud.org/pdf/ptp/v13n2/v13n2a12.pdf.

51. Vieira JS, Gonçalves VB, Martins MFD. Trabalho docente e saúde das professoras de educação infantil de Pelotas, Rio Grande do Sul. Trab Educ Saúde. 2016;14(2):559-74. PMid:19817746. http://dx.doi.org/10.1590/19817746-sip00119.

52. Canova KR, Porto JB. O impacto dos valores organizacionais no estresse ocupacional: um estudo com professores de ensino médio. Rev Adm Mackenzie. 2010;11(5):4-31. PMid:16786971. http://dx.doi.org/10.1590/ S1678-69712010000500002.

53. Villani A, Freitas D, Brasilis R. Professor pesquisador: o caso Rosa. Ciênc Educ. 2009;15(3):479-96. PMid:15167313. http://dx.doi.org/10.1590/ S1516-73132009000300003.

54. Silverio KCA, Gonçalves CGO, Penteado RZ, Vieira TPG, Libardi A, Rossi D. Ações em saúde vocal: proposta de melhoria do perfil vocal de professores. Pró-Fono R Atual Cient. 2008;20(3):177-82. PMid:01045687. http://dx.doi.org/10.1590/S0104-56872008000300007

55. Lima-Silva MFB, Ferreira LP, Oliveira IB, Andrada MA, Silva ACAMG. Distúrbio de voz em professores: autorreferência, avaliação perceptiva da voz e das pregas vocais. Rev Soc Bras Fonoaudiol. 2012;17(4):391-7. PMid:19820232. http://dx.doi.org/10.1590/S1516-80342012000400005.

56. Anhaia TC, Klahr PS, Ourique AAB, Gadenz CD, Fernandes RA, Spagnol $\mathrm{PE}$, et al. Efeitos de duas intervenções em professores com queixas vocais. Audiol Commun Res. 2014;19(2):186-93. PMid:23176431. http://dx.doi. org/10.1590/S2317-64312014000200014.

57. Xavier IALN, Santos ACO, Silva DM. Saúde vocal do professor: intervenção fonoaudiológica na atenção primária à saúde. Rev CEFAC. 2013;15(4):97685. PMid:19820216. http://dx.doi.org/10.1590/S1516-18462013000400027.

58. Luchesi KF, Mourão LF, Kitamura S. Ações de promoção e prevenção à saúde vocal de professores: uma questão de saúde coletiva. Rev CEFAC. 2010;6(6):945-53. PMid:19820216. http://dx.doi.org/10.1590/S151618462010005000112

59. Pereira LPP, Masson MLV, Carvalho FM. Aquecimento vocal e treino respiratório em professores: ensaio clínico randomizado. Rev Saude Publica. 2015;49:67. http://dx.doi.org/10.1590/S0034-8910.2015049005716. PMid:26465664.

60. Penteado RZ, Ribas TM. Processos educativos em saúde vocal do professor: análise da literatura da Fonoaudiologia brasileira. Rev Soc Bras Fonoaudiol. 2011;16(2):233-9. PMid:19820232. http://dx.doi.org/10.1590/S151680342011000200020

61. Lima A, Althaus D. Formação docente continuada, desenvolvimento de práticas pedagógicas em sala de aula e promoção da saúde do professor: relações necessárias. Rev Bras Estud Pedagogicos. 2016;97(245):97-116. PMid:00347183. http://dx.doi.org/10.1590/S2176-6681/366113867.

62. Jotz CB, Seminotti NA, Fritsch R. Produção da subjetividade e de saúde no trabalho docente: o grupo como estratégia de reflexão da prática do professor. Educ Rev. 2015;31(1):93-114. PMid:01024698. http://dx.doi. org/10.1590/0102-4698126527.

63. Penteado RZ, Pereira IMTB. Qualidade de vida e saúde vocal de professores. Rev Saude Publica. 2007;41(2):236-43. PMid:17384799. http://dx.doi. org/10.1590/S0034-89102007000200010.

64. Penteado RZ. Relações entre saúde e trabalho docente: percepções de professores sobre saúde vocal. Rev Soc Bras Fonoaudiol. 2007;12(1):18-22. PMid:19820232. http://dx.doi.org/10.1590/S1516-80342007000100005.

65. Mancebo D. Trabalho docente: subjetividade, sobre implicação e prazer. Psicol Reflex Crit. 2007;20(1):74-80. PMid:16787153. http://dx.doi.org/10.1590/ S0102-79722007000100010.

66. Wilberstaedt IOS, Vieira MGM, Silva YF. Saúde e qualidade de vida: discursos de docentes no cotidiano de uma escola pública de Santa Catarina. Trab Educ Saúde. 2016;14(1 Suppl):219-38. PMid:16781007. http://dx.doi. org/10.1590/1981-7746-sol00026.

67. Stanga AC, Rezer R. Concepções de saúde, trabalho docente e o Pró-Saúde: nos caminhos da hermenêutica. Physis. 2015;25(2):593-614. PMid:01037331. http://dx.doi.org/10.1590/S0103-73312015000200014.

68. Santos KF, Bógus CM. A percepção de educadores sobre a escola promotora de saúde: um estudo de caso. Rev Bras Crescimento Desenvolv Hum. 2007 [citado em 2017 jan 1];17(3):123-33. PMid:21753598. Disponível em: http:// pepsic.bvsalud.org/pdf/rbcdh/v17n3/12.pdf.

69. Barros ME, Zorzal D, Almeida F, Iglesias R, Abreu V. Saúde e trabalho docente: a escola como produtora de novas formas de vida. Trab Educ Saúde. 2007;5(1):103-23. PMid:19817746. http://dx.doi.org/10.1590/ S1981-77462007000100005.

70. Marques EP, Pelicioni MC, Pereira IM. Educação Pública: falta de prioridade do poder público ou desinteresse da sociedade? Rev Bras Crescimento Desenvolv Hum. 2007 [citado em 2017 jan 1];17(3):8-20. PMid:21753598. Disponível em: http://pepsic.bvsalud.org/pdf/rbcdh/v17n3/02.pdf.

71. Cacciari FR, Lima FTD, Bernardi MR. Ressignificando a prática: um caminho para a inclusão. Constr Psicopedag. 2005 [citado em 2017 jan 1];13(10):13-28. PMid:14156954. Disponível em: http://pepsic.bvsalud.org/ scielo.php?script=sci_arttext\&pid=S1415-69542005000100011.

72. Karmann D F, Lancman S. Professor-intensificação do trabalho e o uso da voz. Audiol Communic Res. 2013;18(3):162-70. PMdi:23176341. http:// dx.doi.org/10.1590/S2317-64312013000300005.

73. Lopes MCR. Universidade produtiva" e trabalho docente flexibilizado. Est Pesq Psicol. 2006;6(1):35-48. PMid:18084281.

74. Garcia MMA, Anadon SB. Reforma educacional, intensificação e autointensificação do trabalho docente. Educ Soc. 2009;30(106):63-85. PMid:01017330. http://dx.doi.org/10.1590/S0101-73302009000100004.

75. Santos LLCP. Formação de professores na cultura do desempenho. Educ Soc. 2004;25(89):1145-57. PMid: 01017330. http://dx.doi.org/10.1590/ S0101-73302004000400004

76. Moura EG. Gestão do trabalho docente: o "dramático" uso de si. Educ Rev. 2009;(33). PMid:19840411. http://dx.doi.org/10.1590/S010440602009000100011. 
77. Scoz BJL. Subjetividade de professoras/es: sentidos do aprender e do ensinar. Psicologia da Educação. 2008 [citado em 2017 jan 1];26:5-27. PMid:21753520. Disponível em: http://pepsic.bvsalud.org/pdf/psie/n26/v26a02.pdf.

78. Lago RR, Cunha BS, Borges MFSO. Percepção do trabalho docente em um Universidade da região Norte do Brasil. Trab Educ Saúde. 2015;13(2):42950. PMid:19817746. http://dx.doi.org/10.1590/1981-7746-sip00049.

79. Santos GB. Trabalho docente: a cristalização de uma metáfora. Trab Educ Saúde. 2015;13(3):565-80. PMid: 16781007. http://dx.doi.org/10.1590/19817746-sol00004.

80. Servilha EAM, Leal ROF, Hidaka MTU. Riscos ocupacionais na legislação trabalhista brasileira: destaque para aqueles relativos à saúde e à voz do professor. Rev Soc Bras Fonoaudiol. 2010;15(4):505-13. PMid:19820232. http://dx.doi.org/10.1590/S1516-80342010000400006.

81. Ferreira LP, Servilha EAM, Masson MLV, Reinaldi MBFM. Políticas públicas e voz do professor: caracterização das leis brasileiras. Rev Soc Bras
Fonoaudiol. 2009;14(1):1-7. PMid:19820232. http://dx.doi.org/10.1590/ S1516-80342009000100003.

82. Witter GP. Professor-estresse: análise de produção científica. Psicol Esc Educ. 2003;7(1):1-17. PMid:217532539. http://dx.doi.org/10.1590/S141385572003000100004 .

83. Ribas TM, Penteado RZ, García-Zapata MTA. Qualidade de vida relacionada à voz de professores: uma revisão sistemática exploratória da literatura. Rev CEFAC. 2014;16(1):294-306. PMid:19820216. http://dx.doi. org/10.1590/1982-021620144812.

84. Almeida SIC, Pontes P, Bussacos MA, Neves L, Zambon F. Questionário de auto-avaliação vocal: instrumento epidemiológico de controle da síndrome disfônica ocupacional em professores. Arq Int Otorrinolaringol. 2010;14(3):316-21. PMid:18094872. http://dx.doi.org/10.1590/S180948722010000300008

Recebido em: Jan. 01, 2017 Aprovado em: Fev. 12, 2017 